\title{
Bulked-segregant Analysis Identified a Putative Region Related to Short Internode Length in Melon
}

\author{
Taifeng Zhang, Jiajun Liu, Shi Liu, Zhuo Ding, Feishi Luan, \\ and Peng Gao ${ }^{1}$ \\ College of Horticulture and Landscape Architecture, Northeast Agricultural \\ University, Harbin, Heilongjiang 150030, China; and Key Laboratory of \\ Biology and Genetic Improvement of Horticulture Crops (Northeast Region), \\ Ministry of Agriculture, Harbin, Heilongjiang 150030, China
}

Additional index words. Cucumis melo, short internodes, dwarf, genetic linkage

\begin{abstract}
Short internode length (SIL) is one of the most commercially and important traits in melon varieties (Cucumis melo L.). SIL can result in a compact vining type that promotes concentrated fruit in high-density crops, leading to greater use of light resources for photosynthesis and greater yield per unit area. In our study, two parental melon lines 'M1-32' ( $P_{1}$, standard vine) and 'X090' $\left(P_{2}\right.$, short internodes), and their $F_{1}, F_{2}$, $B C_{1} P_{1}$, and $B C_{1} P_{2}$ progenies were evaluated after being grown in plastic greenhouse conditions in 2017 and 2018. Main stem length (MSL) and internode length (IL) of six melon generations indicated that a single recessive gene (MD7) controlled dwarfism in the 'X090' melon line. Whole-genome analysis revealed a genomic region harboring the candidate dwarfism gene on chromosome 7. Six polymorphic cleaved amplified polymorphic sequence (CAPS) markers from chromosome 7 were used to construct a genetic linkage that spanned $30.28 \mathrm{cM}$. The melon dwarfing locus $M D 7$ responsible for SIL was positioned between markers M7-4 and M7-5, with 3.16 cM of flanking distance. The CAPS markers M7-4 and M7-5 developed have the potential to accelerate the development of dwarf melon varieties, especially in situations when dwarf genotypes are an important breeding goal using marker-assisted selection.
\end{abstract}

According to the Food and Agriculture Organization, China was the largest melon producer and consumer, accounting for $50.04 \%$ of the total production worldwide in 2014 [as cited in Sun et al. (2017)]. Compact or dwarf crops have great agricultural advantages, including greater planting density and resistance to storm and lodging, and reduced losses during harvesting operations (Amasino et al., 2003).

Many dwarf crop traits, including short internodes, short MSL, and bush-type growth habits, have been reported in watermelon [Citrullus lanatus (Thumb.)]. In watermelon, two allelic genes $\left(d w-1\right.$ and $\left.d w-1^{s}\right)$ and three independent loci $(d w-2, d w-3$, and $d w-4)$ have been shown to control dwarfism (Huang et al., 1998; Loy and Liu, 1972; Yang et al., 2010). The recessive gene $d w-1$ was discovered in the first dwarf watermelon that was mutated from the standard vining water-

Received for publication 20 Mar. 2019. Accepted for publication 15 May 2019.

Supported by the National Nature Science Foundation of China (no. 31672177), the "Academic Backbone" Project of Northeast Agricultural University (no. 16XG06), the "Young Talents" Project of Northeast Agricultural University (no. 14QC09), and the College Youth Innovation Talent Training Project of Heilongjiang Province (no. UNPYSCT-2016136).

${ }^{1}$ Corresponding author. E-mail: gaopeng_neau@ 163.com. melon inbred line 'WB-2' (Mohr, 1956), which has short internodes formed by abnormal internode cells. The recessive gene $d w-2$ was identified in the short vining variety "Bush Desert King," which has substandard internodes. Subsequently, the simply inherited recessive gene $d w-1^{s}$ was detected in the short vining watermelon variety "Somali Local" (Dyutin and Afanas'eva, 1987), whereas $d w-4$ in the short vining habit was identified in the self-pollinated population of the '5-6y' watermelon (Yang et al., 2010). Furthermore, a potential dwarf candidate gene has been mapped to chromosome 7 and named Cla010726 (Dong et al., 2018). In cucumber, $c p$ and $c p 2$, and $d w$ gene expression have been reported to be responsible for compact and dwarf-type cucumber, respectively (Robinson and Mishanec, 1965; Kauffman and Lower, 1976). A recent study revealed a gene association with short vining habit on chromosome 4 of the cucumber; this gene is highly homologous with cytokinin oxidase $(C K X)$ (Li et al., 2011). A dwarf gene was mapped a dwarf gene to a $2.29 \mathrm{cM}$ with interval using random amplified polymorphic DNA markers in near-isogenic lines (NILs) derived from the pumpkin Ail0 variety ( $\mathrm{Li}$ et al., 2007). In melon, three recessive loci-si-1, si-2, and si3 -were reported to control compactness or dwarfism in 'UC Top Mark bush', 'Persia202', and 'Maindwarf', respectively (Knavel, 1988, 1990; Paris et al., 1984). Furthermore, Hwang et al. (2014) identified the dwarf gene $m d w l$ of the melon 'PNU-WT1' dwarf mutant on chromosome 7, which is highly homologous with $C K X$.

Bulked-segregant analysis (BSA) is an advanced method to identify markers rapidly that are linked tightly to causal genes underlying a given phenotype. In 1991, BSA was used for the first time to map disease-resistant genes (Michelmore et al., 1991). Since then, BSA has been widely used for rapid gene mapping and identification of molecular markers linked to a quantitative or qualitative trait of interest in horticultural crops, including watermelon (Dong et al., 2018), melon (Li et al., 2017), cucumber (Zhang et al., 2015), and tomato (Zhao et al., 2016). In our study, we used a combination of BSA and wholegenome resequencing to characterize the molecular inheritance of dwarfing genes associated with the diminutive plant habit of the melon line 'X090', and developed molecular markers for marker-assisted breeding of dwarf melon cultivars in China.

\section{Materials and Methods}

Plant materials. Two melon parental lines 'M1-32' $\left(\mathrm{P}_{1}\right.$, female $)$ and 'X090' $\left(\mathrm{P}_{2}\right.$, male $)$ were used to generate the $\mathrm{F}_{1}, \mathrm{~F}_{2}, \mathrm{BC}_{1} \mathrm{P}_{1}$, and $\mathrm{BC}_{1} \mathrm{P}_{2}$ populations. ' $\mathrm{X} 090$ ' is a dwarf type with bush and short internodes, whereas 'M132 ' is a standard type. In 2017, parental lines 'M1-32' $(\mathrm{n}=15)$ and 'X090' $(\mathrm{n}=15)$, and their $F_{2}$ progenies $(n=511)$, and backcross generations $\mathrm{BC}_{1} \mathrm{P}_{1}(\mathrm{n}=150)$ and $\mathrm{BC}_{1} \mathrm{P}_{2}(\mathrm{n}=$ $150)$ were evaluated in a plastic greenhouse. A total of $985 \mathrm{~F}_{2}$ individual melons were planted in 2018. Irrigation, weeding, and pest control were conducted using standard horticultural procedures for typical Harbin climatic conditions.

Phenotypic data collection. MSL and IL were measured, and the number of internodes was recorded for individual plants at the adult stage. CM represents the height of the entire main vine and the length of the vine between the two adjacent leaves in the middle of the main vine. Plants were divided into two phenotypes - S (standard vine) and D (dwarf vine) - based on MSL and IL.

Genomic DNA extraction. Young leaves of $\mathrm{P}_{1}, \mathrm{P}_{2}, \mathrm{~F}_{1}$, and $\mathrm{F}_{2}$ plants without any damage were collected and frozen rapidly at $-80{ }^{\circ} \mathrm{C}$ for storage. Genomic DNA was extracted using the modified cetyltrimethylammonium bromide method (Allen et al., 2006).

Whole-genome resequencing of bulked $D N A$. DNA concentration was measured using an SMA3000 spectrophotometer (Plextech, Shenzhen, China) and was electrophoresed on a $1 \%$ agarose gel. Two bulk DNA samples were prepared by mixing an equal proportion of DNA from 30 standard-type and 30 dwarf-type $F_{2}$ plants. Two bulk and two parental DNA samples were selected for sequencing. Briefly, DNA samples were disrupted using ultrasound, then were repaired distally, ligated with sequencing joints, and separated using $1 \%$ agarose gel electrophoresis to harvest target insert sizes ranging 
from 500 to $600 \mathrm{bp}$ for sequencing. Polymerase chain reaction (PCR) amplification was performed to construct a paired-read sequencing library. The DNA libraries were sequenced using the Illumina HiSeqTM 2500 platform (Biomarker, Beijing, China) to generate 125 base paired-end reads.

BSA analysis. The reads of the dwarf parent ('X090') were first cleaned and then aligned with the melon reference genome (DHL92) using BWA (version 0.6.1-r104), from which merged alignments were sorted and read duplicates were removed using SAMTOOLS's (version 0.1.19) rmdup command. The Unified Genotyper module of GATK3.3 was used to detect multiple samples of single nucleotide polymorphisms (SNPs) and insertions or deletions that were filtered with variant filtration and annotated with ANNOVAR (version Apr16). Associations among target sites were analyzed using the SNP index method to determine the genomic region of the dwarf gene.

$$
\begin{aligned}
\text { SNP index }(\mathrm{aa})= & \frac{\mathrm{Xaa}}{\mathrm{Xaa}+\mathrm{Maa}} \\
\text { SNP index }(\mathrm{bb})= & \frac{\mathrm{Xbb}}{\mathrm{Xbb}+\mathrm{Mbb}} \\
\Delta(\mathrm{SNP} \text { index })= & \text { SNP index }(\mathrm{aa}) \\
& -S N P \text { index }(\mathrm{bb})
\end{aligned}
$$

where X represents 'X090'; M represents 'M1-32'; aa and bb are equal to the genotypes of the $\mathrm{D}$ and $\mathrm{S}$ bulks, respectively; Xaa and Maa represent the depth of the aa population derived from $\mathrm{X}$ and $\mathrm{M}$, respectively; and $\mathrm{Xbb}$ and $\mathrm{Mbb}$ represent the depth of the bb population derived from $\mathrm{X}$ and $\mathrm{M}$, respectively. The stronger the correlations between SNPs and dwarf traits, the closer $\Delta(\mathrm{SNP}$ index $)$ is to one. $\Delta(\mathrm{SNP}$ index $)=0$ represents no association of SNP with dwarf trait.

CAPS marker development. The dwarf gene was positioned on the target chromosome and mapped using the melon (DHL92) reference genome from the BSA results. Sequencing data underwent a series of quality control procedures using Perl scripts of Northeast Agricultural University to select different candidate sequences of $\approx 500 \mathrm{bp}$ carrying restriction site-specific SNPs using SNP2CAPS software. The SNP loci were converted to CAPS markers.

Validation of CAPS markers by PCR. The PCR product was cleaved by respective endonucleases to identify the polymorphism of the CAPS markers between two parental lines and their $\mathrm{F}_{1}$. PCR amplification was performed using the touchdown PCR reaction (Amanullah et al., 2018), which contained $2 \mu \mathrm{L}$ template DNA, $0.4 \mu \mathrm{L}$ Taq endonuclease, $1 \mu \mathrm{L}$ of each forward and reverse primer, $2 \mu \mathrm{L}$ Taq buffer, $0.6 \mu \mathrm{L}$ dNTPs, and $13 \mu \mathrm{L}$ double-distilled water in a total volume of $20 \mu \mathrm{L}$. The PCR amplification was programmed as follows: preheat- ing at $94{ }^{\circ} \mathrm{C}$ for $7 \mathrm{~min}$, followed by 30 cycles of heating at $94{ }^{\circ} \mathrm{C}$ for $1 \mathrm{~min}, 60{ }^{\circ} \mathrm{C}$ renaturation for $30 \mathrm{~s}$, cool-down at $0.5{ }^{\circ} \mathrm{C}$ and extension at $72{ }^{\circ} \mathrm{C}$ for $90 \mathrm{~s}$, and finally extension at $72{ }^{\circ} \mathrm{C}$ for $10 \mathrm{~min}$. The PCR product was separated using $1 \%$ agarose gel electrophoresis and digested with five restriction enzymes (PstI, MspI, MboI, HindIII, and $S a c 1)$. The digestion reaction contained $5 \mu \mathrm{L}$ PCR product, $0.3 \mu \mathrm{L}$ restriction enzymes (concentration $10 \mathrm{U} \cdot \mathrm{mL}^{-1}$ ), $1.5 \mathrm{~mol} \cdot \mathrm{L}^{-1}$ enzyme corresponding buffer, and $8.2 \mu \mathrm{L}$ double-distilled water in a total volume of 15 $\mu \mathrm{L}$ at 37 or $65^{\circ} \mathrm{C}$ constant temperature in an incubator for $3 \mathrm{~h}$ depending on the endonuclease.

Genetic linkage map construction. Genetic linkage maps were constructed using quantitative trait loci (QTL) Ici mapping in which standard-vine $F_{2}$ individuals were recorded as 2 and dwarf individuals were recorded as 1 . The interval mapping analysis of gene loci was also performed to determine genetic distances using QTL Ici mapping (version 4.0).

Statistical analysis. Variance and difference analysis of field phenotypic data was performed using statistical software (SPSS 23.0) and Microsoft Excel 2007.

\section{Results}

Inheritance of dwarf habit. As shown in Fig. $1 \mathrm{C}$ and $\mathrm{D}$, there were significant morphologic differences between the 'X090' and 'M1-32' plants during the third true-leaf stage. The average MSL of dwarf plants did not exceed $50 \mathrm{~cm}$, whereas the average MSL
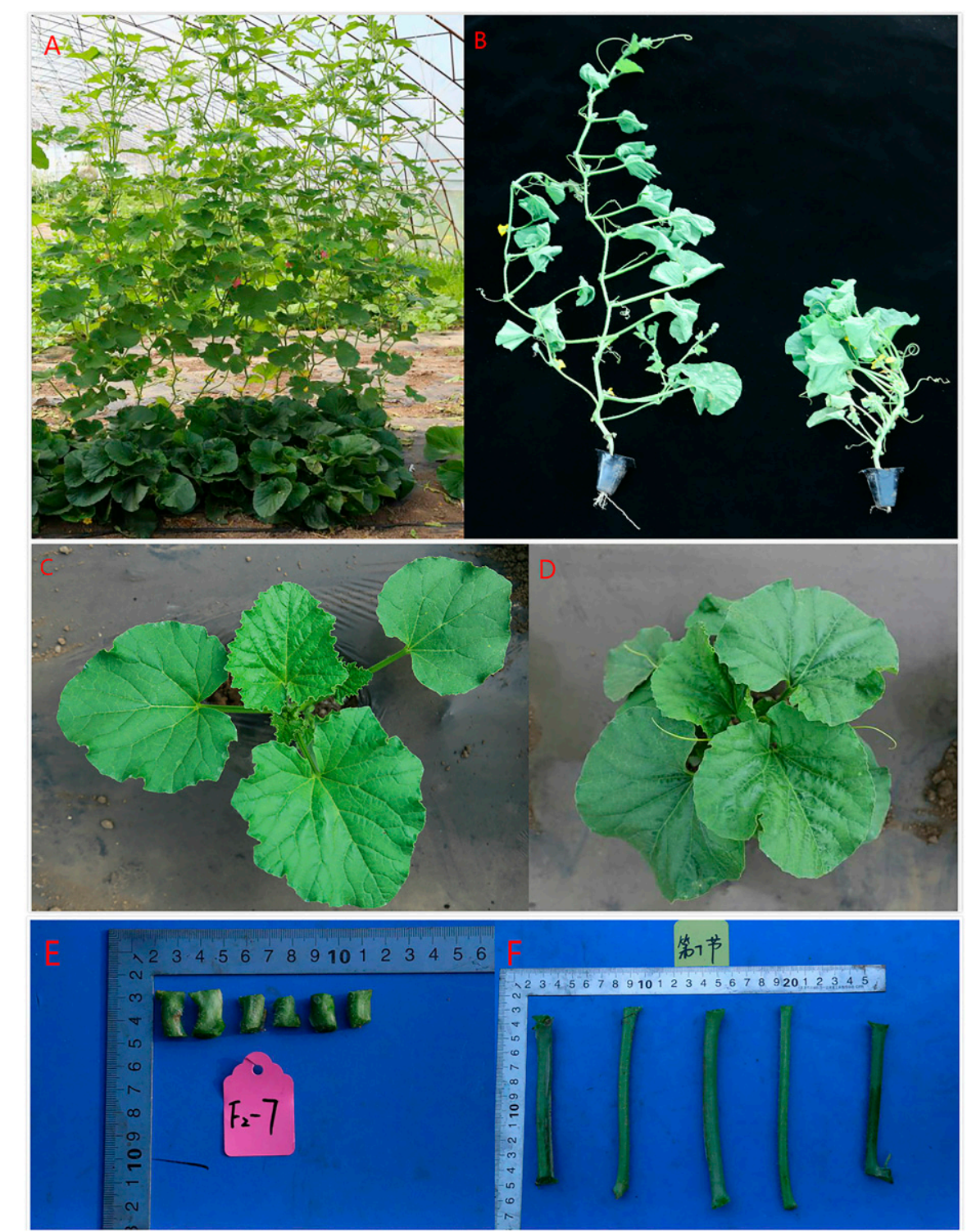

Fig. 1. Differences in plant characteristics between the dwarf melon line ' $\mathrm{X} 090$ ' and the standard vining line 'M1-32' cultivated in a plastic greenhouse. (A) 'M1-32' mature plant with standard vine (behind) and 'X090' adult plant with short vine (front). (B) Segregation in $\mathrm{F}_{2}$ progenies, standard-type (left) and dwarf-type (right). (C) Standard-type $F_{2}$ plant 23 to $25 \mathrm{~d}$ after seeding. (D) Dwarf-type $\mathrm{F}_{2}$ plant 23 to $25 \mathrm{~d}$ after seeding. (E) CM measurement in dwarf-type $\mathrm{F}_{2}$ plants. (F) CM measurement in standardtype $\mathrm{F}_{2}$ plants. $\mathrm{CM}$ represents the height of the entire main vine and the length of the vine between the two adjacent leaves in the middle of the main vine. 
Internode length comparison

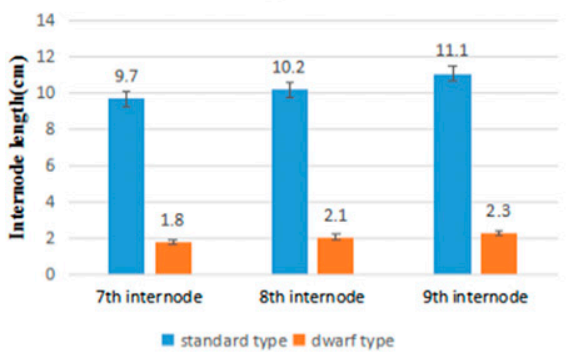

Primary stem length

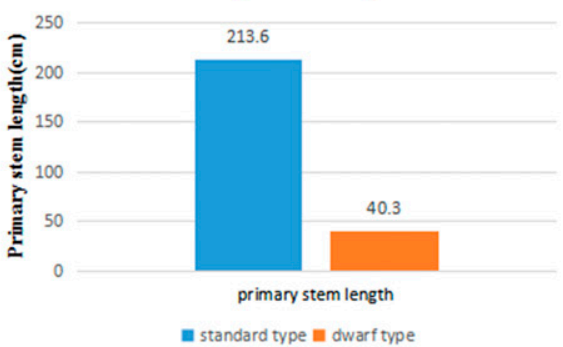

Number of internodes of primary stem

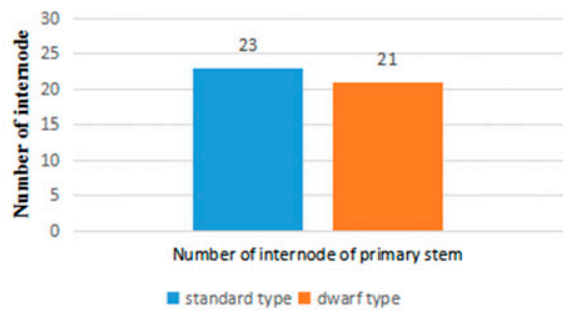

Fig. 2. Comparisons of (A) internode length at the seventh, eighth, and ninth internodes; (B) main stem length, and (C) number of internodes between standard vines and dwarf vines.

Table 1. Phenotypic performance of six generations from the 2017 and 2018 greenhouse evaluation.

\begin{tabular}{|c|c|c|c|c|c|c|c|}
\hline $\mathrm{Yr}$ & Generation & $\mathrm{S}$ & D & Expected ratio & Actual ratio & $\chi^{2}$ value & $P$ value \\
\hline 2017 & $\mathrm{P}_{1}$ & 15 & 0 & - & - & - & - \\
\hline 2017 & $\mathrm{~F}_{1}$ & 15 & 0 & - & - & - & - \\
\hline 2017 & $\mathrm{BC}_{1} \mathrm{P}_{1}$ & 150 & 0 & - & - & - & - \\
\hline 2017 & $\mathrm{~F}_{2}$ & 393 & 118 & $3: 1$ & $3.33: 1$ & 0.992 & 0.319 \\
\hline 2018 & $\mathrm{~F}_{2}$ & 750 & 235 & $3: 1$ & $3.19: 1$ & 0.685 & 0.408 \\
\hline
\end{tabular}

$\mathrm{S}=$ standard vine; $\mathrm{D}=$ dwarf vine

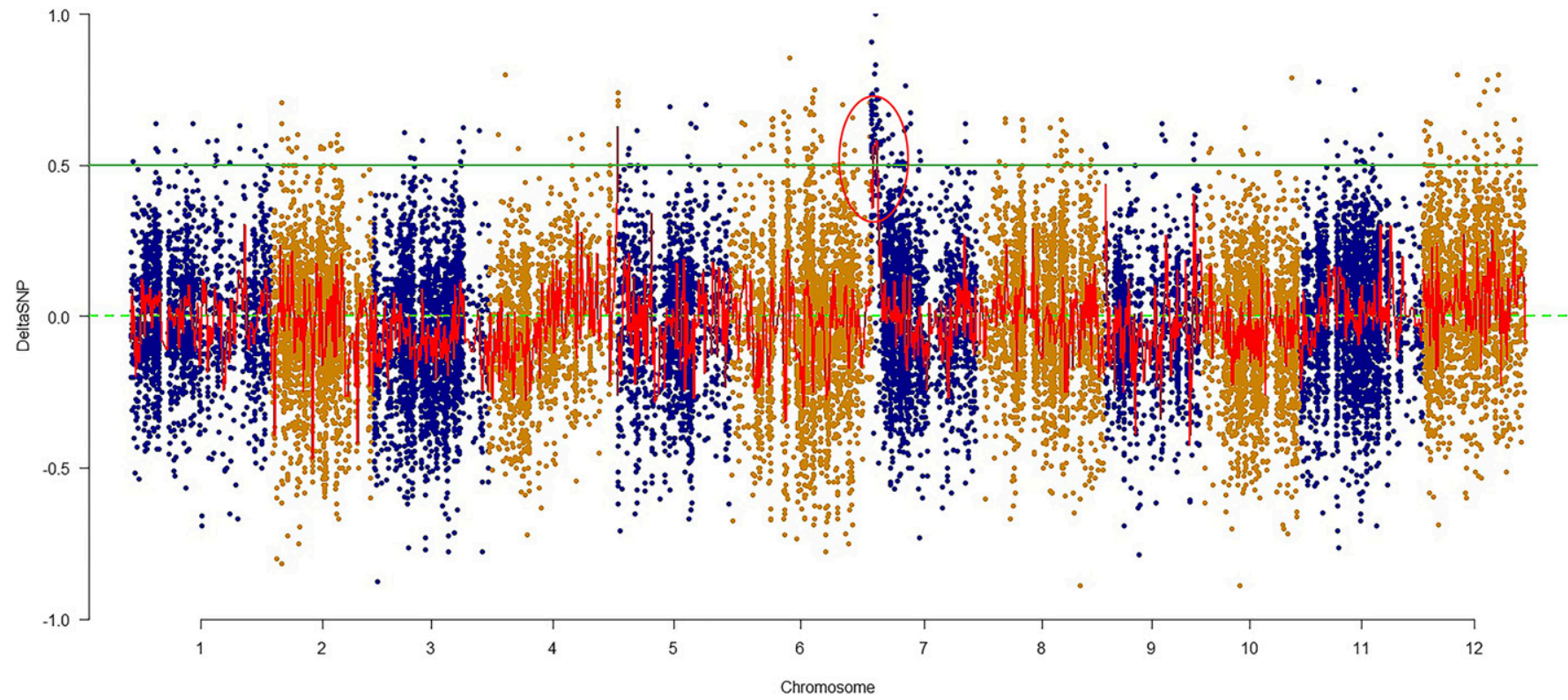

Fig. 3. Calculated single nucleotide polymorphism (SNP) index plots across the whole genome. The $\mathrm{x}$-axis indicates the position of 12 chromosomes in the melon; the y-axis represents the SNP index. The dashed line (green in online figure) is the threshold value calculated by Loess regression $(0.5)$. The circle (red in online figure) on chromosome 7 represents a significant fluctuation peak.

of standard plants exceeded $200 \mathrm{~cm}$ in the adult stage. Among the $\mathrm{F}_{2}$ progenies examined (Fig. 1A and B), the average ILs of the seventh, eighth, and ninth internodes in dwarf plants were $1.8 \mathrm{~cm}, 2.1 \mathrm{~cm}$, and $2.3 \mathrm{~cm}$, respectively; whereas the average ILs in standard plants were $9.7 \mathrm{~cm}, 10.2 \mathrm{~cm}$, and $11.1 \mathrm{~cm}$, respectively. The average MSL in standard plants was $213.6 \mathrm{~cm}$ with an average of 24 internodes, but the average MSL in dwarf plants was $40.3 \mathrm{~cm}$ with an average of 21 internodes (Fig. 2).

Both the $\mathrm{F}_{1}$ and $\mathrm{BC}_{1} \mathrm{P}_{1}$ generations behaved as standard plants whereas the $\mathrm{BC}_{1} \mathrm{P}_{2}$ generation exhibited a 1:1 ratio of standard $(\mathrm{n}=78)$ to dwarf $(\mathrm{n}=76)\left(\chi^{2}=0.24, P=\right.$ $0.624)$. Among the $511 \mathrm{~F}_{2}$ progenies examined in 2017, the ratio of standard $(n=393)$ to dwarf $(\mathrm{n}=118)$ conformed to Mendelian $\mathrm{F}_{2}$ segregation ratios of $3: 1\left(\chi^{2}=0.992, P=\right.$ $0.319)$. Among the $985 \mathrm{~F}_{2}$ progenies examined in 2018, 750 were segregated standard and 235 were dwarf, further supporting the previously observed $3: 1$ phenotypic segregation pattern for this trait $\left(\chi^{2}=0.685\right.$, $P=0.408$ ) (Table 1). These results indicate that a single recessive gene controls dwarfism in 'X090', named MD7.
BSA-identified candidate gene controlling dwarfism on chromosome 7 (Fig. 3). The DNA pool with mixed dwarf and standard vining plants was sequenced by the Beijing Genomics Institute to generate the preliminary BSA positioning results, which ranged from 0.35 to $1.8 \mathrm{Mb}$ on chromosome 7 , respectively (Fig. 4). As shown in Fig. 3, one significant peak fluctuation was located on chromosome 7 , suggesting that genes controlling dwarf traits might be positioned on chromosome 7.

CAPS primer screening and verification. Resequencing results based on the parental 


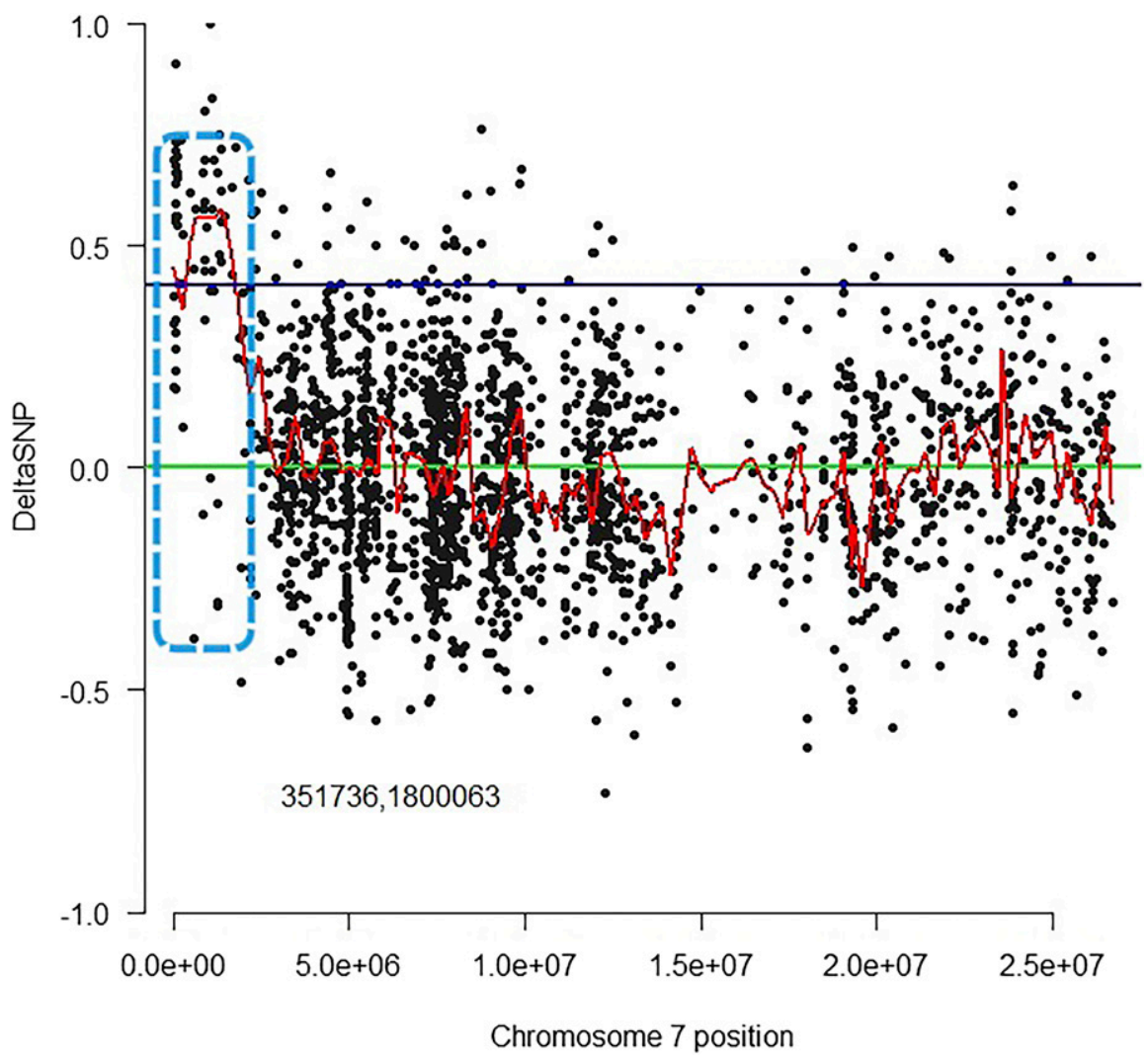

Fig. 4. Single nucleotide polymorphism index plots across chromosome 7. A candidate gene region is framed with a dashed line (blue in the online figure) ranging from 0 to $1.8 \mathrm{Mb}$. genome were used to design 10 pairs of CAPS primers for chromosome 7. PCR and restriction enzyme digestion were performed using DNA from both contrasted parents and $F_{1}$ plants. Among them, six pair of primers had a polymorphism between 'X090' and 'M1-32' accounting for $60 \%$ of the polymorphic rate.

Genetic linkage map construction. To map dwarf genes on chromosome 7, six pairs of polymorphic CAPS markers were used to construct a genetic linkage map using $1496 \mathrm{~F}_{2}$ progenies (Fig. 5A). This unsaturated melon map spanned $30.28 \mathrm{cM}$ with six CAPS markers; the melon dwarf locus MD7 was positioned between markers M7-4 and M7-5 (Fig. 5B), with $3.16 \mathrm{cM}$ of flanking distance. The physical distance between the two markers M7-4 and M7-5 was $196 \mathrm{~Kb}$, ranging from $1,059,752$ to $1,255,618$ bp. All six markers used for mapping are listed in Table 2 .

Candidate genes analysis. There were 25 genes (MELO3C016908-MELO3C016932) found between the markers M7-4 and M7-5. Of these genes, eight contained 11 nonsynonymous SNPs (Table 3), seven genes have more detailed annotation when blasting them against $A$. thaliana genes, which from TAIR10 (https://www.arabidopsis.org/). MELO3C016912 encodes SLOMO (slow motion), an F-box protein required for auxin homeostasis and normal timing of lateral organ initiation at the shoot meristem. MELO3C016915 is a P-Type adenosine triphosphatase and mediates copper

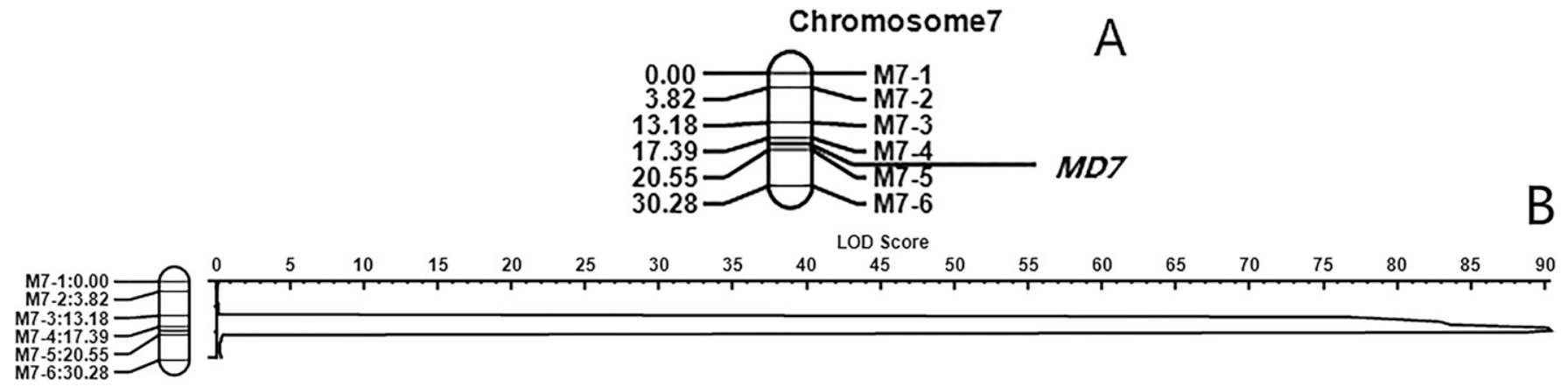

A

Fig. 5. Position of the dwarf gene on chromosome 7. (A) Linkage map of six markers in the candidate region. The total map distance was $30.28 \mathrm{cM}$ and the average distance between the markers was $5.05 \mathrm{cM}$. (B) Quantitative trait loci curve of melon MD7. The peak logarithm of the odds (LOD) value of the genetic linkage map between markers M7-4 and M7-5 was 90.7 .

Table 2. CAPS markers used to map MD7.

\begin{tabular}{|c|c|c|c|}
\hline Marker & Primer sequence $\left(5^{\prime} \rightarrow 3^{\prime}\right)$ & Enzyme & Annealing temp $\left({ }^{\circ} \mathrm{C}\right)$ \\
\hline \multirow[t]{2}{*}{ M7-2 } & F:AGGTTGCTATTATGGTGGAGGT & MspI & 55 \\
\hline & R:ATACATCGCTCTCGTCACAGA & & \\
\hline M7-3 & R:TCTCTATCTACTTCGTTGACAATGG & & \\
\hline \multirow[t]{2}{*}{ M7-4 } & F:CGTCGCCAACCTTCCTCTAT & HindIII & 55 \\
\hline & R:CCAAAGGCTCGTGCGTTTA & & \\
\hline \multirow[t]{2}{*}{ M7-6 } & F:GCATCATAGTCCAAGGTGAATATAC & PstI & 55 \\
\hline & R:ACGGTAGTCTCAGTAGCAACA & & \\
\hline
\end{tabular}

CAPS $=$ cleaved amplified polymorphic sequence. 
Table 3. All nonsynonymous mutated genes between markers M7-4 and M7-5.

\begin{tabular}{|c|c|c|c|}
\hline Gene ID & nsSNPs numbers & Physical location & Gene annotation \\
\hline$\overline{M E L O 3 C 016912 ~}$ & 1 & chr7: 1192085 .. 1199707 (-) & F-box/LRR-repeat protein 15 \\
\hline MELO3C016915 & 1 & chr7: 1178459 .. $1187249(-)$ & Putative copper-transporting ATPase 3 \\
\hline MELO3C016916 & 1 & chr7: 1163457 .. $1171401(-)$ & Putative receptor protein kinase \\
\hline MELO3C016918 & 1 & chr7: $1153115 . .1157656(+)$ & Chalcone-flavonone isomerase family protein \\
\hline MELO3C016922 & 3 & chr7: 1117577 .. $1117792(-)$ & DNA-directed RNA polymerase subunit omega \\
\hline MELO3C016925 & 2 & chr7: 1100697 .. $1103705(-)$ & Pentatricopeptide repeat-containing protein \\
\hline MELO3C016926 & 1 & chr7: 1092715 .. $1099611(-)$ & DNA crosslink repair $1 \mathrm{~A}$ protein \\
\hline MELO3C016932 & 1 & chr7: $1060848 \ldots 1063679(+)$ & Coffea canephora $\mathrm{DH} 200=94$ genomic scaffold, scaffold_103 \\
\hline Total & 11 & & \\
\hline
\end{tabular}

nsSNPs = nonsynonymous single nucleotide polymorphisms; LRR = leucine-rich repeat; ATPase = adenosine triphosphatase.
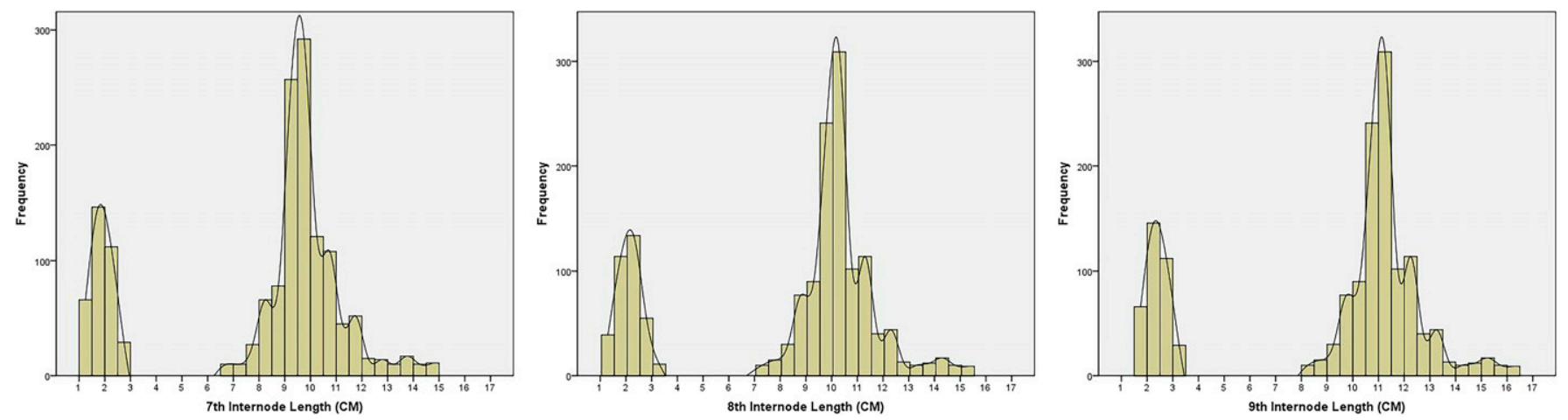

Fig. 6. Frequency distribution of internode lengths (ILs) at the seventh, eighth, and ninth internodes in all $\mathrm{F}_{2}$ progenies examined in 2017 and 2018.

transport to chloroplast thylakoid lumen. MELO3C016916 is homologous to receptor protein kinases and is involved in the specification of organs originating from the shoot apical meristem. MELO3C016918 encodes a plastid stroma localized fatty acid binding protein. MELO3C016925 is a tetratricopeptide repeatlike superfamily protein. $M E L O 3 C 016926$ is a sterile alpha motif domain-containing protein. MELO3C016932 is an initiation factor 4F subunit (DUF1350).

\section{Discussion}

Dwarfism is one of the most commercially important traits in melon breeding because of its positive effect on yield and the associated decreased labor required for cultivation and harvest. In China, two planting methods (creeping and hanging vine cultivation) are widely used for melon production in greenhouses, among which creeping vine cultivation is predominant to cover the production area. Hanging vine cultivation greatly reduces row and plant space because of the upward growth of the plants, leading to significant increases in yield. In greenhouse conditions, $\approx 1200$ melon plants/acre can be grown using creeping cultivation, whereas $\approx 2100$ plants, with $30 \times 35$-cm plant spacing per acre, can be cultivated using hanging vines. Melon vining habit is a key determinant of cultivation methods. Diminutive dwarf-type melons provide an alternative to standard vining types for plastic tunnel production because of their amenability to low maintenance in upright cultivation. Therefore, there is a strong need to identify dwarfism genes and alleles to develop new dwarf melon varieties.
Dwarfism in melons is caused mainly by SIL, with different phenotypes. Dwarf types can be divided roughly into two categories according to degrees of angles between the side branch and the main vine, and between the direction of the petiole extension and the vine. The compact dwarf type has angles less than $30^{\circ}$ and the loose dwarf type has angles greater than $30^{\circ}$. In our study, we positioned the dwarf gene from the melon line 'X090' on chromosome 7, consistent with the results of Hwang et al. (2014), who reported dwarf gene $m d w 1$ from the diminutive (short internodes) melon mutant line 'PNU-D1'. However, 'PNU-D1' belongs to the loose dwarf type according to seedling and adult pictures (Hwang et al., 2014), whereas the 'X090' line used in our study is a compact dwarf type with very small angle degrees between the side branch and the main vine, as well as between the direction of the petiole extension and the vine (Fig. 1). The side branches of 'X090' appear to be very crowded and oval shaped as a result of the reduced IL. Dwarf genes detected in 'X090' are hypothesized to differ from $m d w l$ in 'PNU-D1', which likely controls the compact dwarf type. In comparison to the loose dwarf type, the compact dwarf type can save planting space with greater density and greater resistance to lodging and storms, resulting in an increased yield and economic efficiency.

IL varies according to the order of internodes in the main vine stem of a melon. The closer to the root, the shorter the IL. Determination of the measurement of the primary stem length between nodes is essential for differentiating dwarf types clearly and mapping candidate genes/QTLs associated with dwarfism. Previous studies measured the IL between the 10th and 15th segments. In our study, standard and dwarf types were distinguished clearly by measuring the IL between the seventh and ninth sections, showing that the dwarfism of ' $\mathrm{X} 090$ ' is attributed to reduced IL instead of to the reduced number of internodes. Therefore, IL at the seventh node was used to divide plants roughly by phenotype into two classes: standard, IL range of 6.5 to $15 \mathrm{~cm}$; and dwarf, IL range of 1 to $3 \mathrm{~cm}$ (Fig. 6). IL increased with the order of internodes. IL of standard vining and dwarf vining plants showed a frequency distribution of the qualitative trait, with mendelian $F_{2}$ segregation ratios of $3: 1$, confirming that dwarfism in ' $\mathrm{X} 090$ ' is governed by a recessive gene (MD7) regulating IL. The dwarf gene in 'X090' was positioned on chromosome 7 and mapped between the two CAPS markers with 3.16 $\mathrm{cM}$ using $1496 \mathrm{~F}_{2}$ plants derived from the cross of 'M1-32' and 'X090'. The developed CAPS markers from chromosome 4 were polymorphic between two parents, but were not co-separated in the $\mathrm{F}_{2}$ population, suggesting no association of chromosome 4 with dwarf traits. Therefore, chromosome 4 was excluded from further validation. Among the 25 genes in this candidate region, eight genes were mutated nonsynonymously. Genome annotation suggested possible effects of MELO3C016912 and MELO3C016916 on the IL. Previous studies revealed the $D D F 1$ gene encodes a leucine-rich repeat (LRR)-type F-box protein that significantly reduces IL and other vegetative organs in rice. MELO3C016912 was also demonstrated to encode an LRR-type F-box protein, affecting IL in melon (Duan et al., 2012). Changes in the 
expression of ERECTA in Arabidopsis affected plant height and floral organ morphology (Torii, 1996), and BLAST alignment revealed high homology of MELO3C016916 to ERECTA. Therefore, MELO3C016916 is hypothesized to affect IL in melon. Further study is needed to characterize the functions of these two genes. The CAPS markers M7-4 and M7-5 have the potential to accelerate the development of dwarf melon varieties using marker-assisted selection. 'X090' appears to be an important donor in melon improvement programs in which dwarf genotypes are an important breeding goal.

\section{Literature Cited}

Allen, G.C., M.A. Flores-Vergara, S. Krasynanski, S. Kumar, and W.F. Thompson. 2006. A modified protocol for rapid DNA isolation from plant tissues using cetyltrimethylammonium bromide. Nat. Protoc. 1:2320-2325.

Amanullah, S., L. Shi, G. Peng, Z. Zhicheng, Z. Qianglong, F. Chao, and L. Feishi. 2018. QTL mapping for melon (Cucumis melo L.) fruit traits by assembling and utilization of novel SNPs based CAPS markers. Scientia Hort. 236:18-19.

Amasino, R.M. 2003. Dwarfism genes and dwarf plants. Wisconsin Alumni Res. Foundation. 1:2.

Dong, W., D. Wu, G. Li, D. Wu, and Z. Wang. 2018. Next-generation sequencing from bulked segregant analysis identifies a dwarfism gene in watermelon. Sci. Rpt. 8:2908.

Duan, Y., S. Li, and Z. Chen. 2012. Dwarf and deformed flower 1, encoding an F-box protein, is critical for vegetative and floral development in rice (Oryza sativa L.). Plant J. 72:829-842.
Dyutin, K.E. and E.A. Afanas'eva. 1987. Inheritance of the short vine trait in watermelon. Cytol. Genet. 21:71-73.

Huang, H., X. Zhang, Z. Wei, Q. Li, and X. Li. 1998. Inheritance of male-sterility and dwarfism in watermelon [Citrullus lanatus (Thunb.) Matsum. and Nakai]. Scientia Hort. 74:175-181.

Hwang, J., J. Oh, Z. Kim, H. Jihyun, O. Juyoul, K. Zoohyun, E.S. Jack, C. Sang-Min, and P. Younghoon. 2014. Fine genetic mapping of a locus controlling short internode length in melon (Cucumis melo, L.). Mol. Breed. 34:949961.

Kauffman, C.S. and R.L. Lower. 1976. Inheritance of an extreme dwarf plant type in the cucumber. J. Amer. Soc. Hort. Sci. 101:150-151.

Knavel, D.E. 1988. Ky-P, short-internode muskmelon. HortScience 23:224.

Knavel, D.E. 1990. Inheritance of a short-internode mutant of 'Mainstream' muskmelon. HortScience 25:1274-1275.

Li, Y.L., H.Z. Li, C.S. Cui, H.Y. Zhang, and G.Y. Gong. 2007. Molecular markers linked to the dwarf gene in squash. J. Agr. Biotechnol. 15(2):279-282. (In Chinese).

Li, Y., L. Yang, M. Pathak, D. Li, X. He, and Y. Weng. 2011. Fine genetic mapping of cp: A recessive gene for compact (dwarf) plant architecture in cucumber Cucumis sativus L. Theor. Appl. Genet. 123:973-983.

Li, B., Y. Zhao, Q. Zhao, Z. Zhipeng, C. Fan, S. Amanullah, P. Gao, and F. Luan. 2017. Mapping of powdery mildew resistance genes in melon (Cucumis melo L.) by bulked segregant analysis. Scientia Hort. 220:160167.

Loy, J.B. and P.B.W. Liu. 1972. Inheritance and morphology of two dwarf mutants in watermelon. J. Amer. Soc. Hort. Sci. 97:745-748.
Michelmore, R.W., I. Paran, and R.V. Kesseli. 1991. Identification of markers linked to disease-resistance genes by bulked segregant analysis: A rapid method to detect markers in specific genomic regions by using segregating populations. Proc. Natl. Acad. Sci. USA 88:98289832.

Mohr, H.C. 1956. Mode of inheritance of the bushy growth characteristics in watermelon. Proc. Assn. Southern Agr. Workers 53:174.

Paris, H.S., H. Nerson, and Z. Karchi. 1984. Genetics of internode length in melons. J. Hered. 75:403-406.

Robinson, R.W. and W. Mishanec. 1965. A new dwarf cucumber. VegImp Newslett. 7:23.

Sun, Y., N. Yang, J. Wu, and X. Wang. 2017. Comparative analysis of the development of watermelon and melon industry in China and the United States. Chinese Melon Veg. 30:1-7. (In Chinese).

Torii, K.U. 1996. The Arabidopsis ERECTA gene encodes a putative receptor protein kinase with extracellular leucine-rich repeats. J. Plant Cell. 8:735-746.

Yang, H., Y. Li, D. Yang, and J. Yang. 2010. A new study on shorter tendril gene of watermelon. J. Chin. Hort. Digest. 26:32-33. (In Chinese).

Zhang, P., Y. Zhu, L. Wang, L. Chen, and S. Chen. 2015. Mining candidate genes associated with powdery mildew resistance in cucumber via super-BSA by specific length amplified fragment (SLAF) sequencing. BMC Genomics 16:1058-1072.

Zhao, T., J. Jiang, G. Liu, S. He, H. Zhang, and X. Chen. 2016. Mapping and candidate gene screening of tomato Cladosporium fulvum-resistant gene $c f-19$, based on high-throughput sequencing technology. BMC Plant Biol. 16:51-60. 